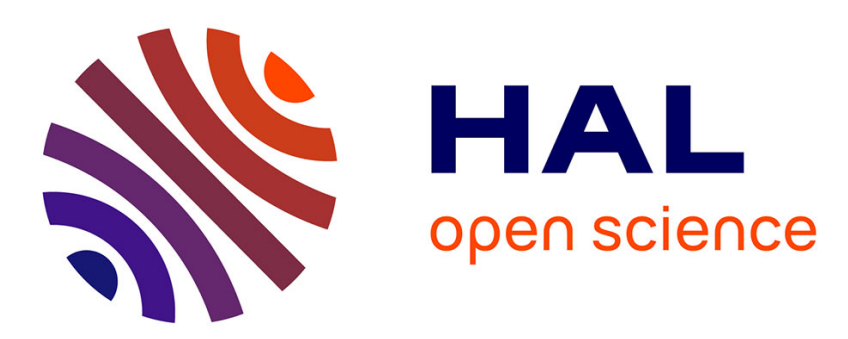

\title{
A simple cathodic process for carboxylating noble metals and generating new versatile electrode interfaces
}

\author{
J. Simonet
}

\section{To cite this version:}

J. Simonet. A simple cathodic process for carboxylating noble metals and generating new versatile electrode interfaces. Electrochemistry Communications, 2017, 85, pp.15-18. 10.1016/j.elecom.2017.09.020 . hal-01639699

\section{HAL Id: hal-01639699}

\section{https://hal-univ-rennes1.archives-ouvertes.fr/hal-01639699}

Submitted on 1 Feb 2018

HAL is a multi-disciplinary open access archive for the deposit and dissemination of scientific research documents, whether they are published or not. The documents may come from teaching and research institutions in France or abroad, or from public or private research centers.
L'archive ouverte pluridisciplinaire HAL, est destinée au dépôt et à la diffusion de documents scientifiques de niveau recherche, publiés ou non, émanant des établissements d'enseignement et de recherche français ou étrangers, des laboratoires publics ou privés. 


\section{Accepted Manuscript}

A simple cathodic process for carboxylating noble metals and generating new versatile electrode interfaces

Jacques Simonet

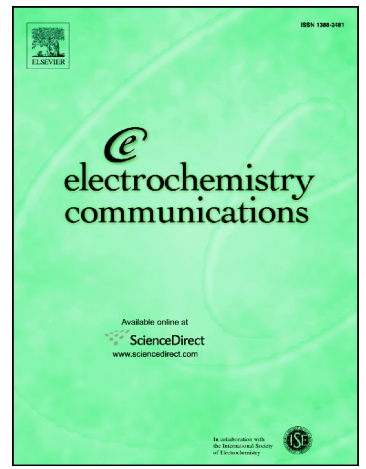

PII:

S1388-2481(17)30271-0

DOI: doi:10.1016/j.elecom.2017.09.020

Reference: ELECOM 6049

To appear in:

Electrochemistry Communications

Received date:

22 August 2017

Revised date:

22 September 2017

Accepted date:

25 September 2017

Please cite this article as: Jacques Simonet, A simple cathodic process for carboxylating noble metals and generating new versatile electrode interfaces. The address for the corresponding author was captured as affiliation for all authors. Please check if appropriate. Elecom(2017), doi:10.1016/j.elecom.2017.09.020

This is a PDF file of an unedited manuscript that has been accepted for publication. As a service to our customers we are providing this early version of the manuscript. The manuscript will undergo copyediting, typesetting, and review of the resulting proof before it is published in its final form. Please note that during the production process errors may be discovered which could affect the content, and all legal disclaimers that apply to the journal pertain. 


\title{
A simple cathodic process for carboxylating noble metals and generating new versatile electrode interfaces
}

\author{
Jacques Simonet ${ }^{*}$ \\ Laboratoire MaCSE, UMR 6226, Université de Rennes 1, Campus de Beaulieu, 35042 \\ Rennes Cedex, France.
}

\begin{abstract}
The electrochemical reactivity of polarized metals such as platinum, palladium, and rhodium toward carbon dioxide in aprotic dimethylformamide (DMF) solutions of tetramethylammonium tetrafluoroborate $\left(\mathrm{TMABF}_{4}\right)$ is presented. The capacity of metals such as $\mathrm{Pd}$ and Pt to cathodically insert the electrolytes under superdry conditions (via the generation of organometallic intermediates analogous to Zintl metals) is combined with the concomitant carboxylation of those metals within a potential range from $-1 \mathrm{~V}$ to $-2.5 \mathrm{~V}$ vs. $\mathrm{Ag} / \mathrm{AgCl} / \mathrm{KCl}$ (sat). Under these conditions, dense surface carboxylation of these precious metals occurs, totally suppressing their catalytic activity. Thick layers of the carboxylated metals (platinum- $\mathrm{CO}_{2}^{-}$and palladium- $\mathrm{CO}_{2}^{-}$) are chemically stable and may then be further functionalized for specific applications.
\end{abstract}

Key words: Cathodic carboxylation; Modified platinum; Modified palladium; Chemically modified solid surfaces.

*Corresponding author: Tel.: +33-23236292; Fax: + 33-23236732

E-mail address: jacques.simonet@univ-rennes1.fr and jacques.simonet@dbmail.com. 


\section{Introduction}

Carbon dioxide has been for long known to be an electro-active gas, under appropriate cathodic reactions quite easily transformable into the products of limited interest that are often considered as by-products. The electrochemical reactivity of carbon dioxide and valorization (via certain reduction processes and modes of its sequestration, green problems, modification of surfaces, catalysis) slowly emerges as a questionable challenge at the present time. Clearly, carbon dioxide remains a bad friend associated to life because it is unavoidably generated in huge excesses by human activity. Electrochemistry plays a major role in cathodic activation of several allotropic forms of carbons [1] like graphite, fullerenes, and glassy carbon that are likely to react with carbon dioxide. This could appear to be of high interest for generating stable carbon carboxylates [2,3]. Additionally, the use of $\mathrm{CO}_{2}$ as a chemical reagent could be realized through its activation at different metallic surfaces under quite selective conditions, consequently considered as catalytic. More specifically, the questionable interest of valorization of $\mathrm{CO}_{2}$ using electro-chemical reduction at different metal catalysts, generally in protic (buffered or unbuffered) conditions is abundantly documented [4-14]. Numerous contributions essentially based on degradation or conversion of $\mathrm{CO}_{2}$ into methanol, carbon monoxide, methane, salts like oxalates, etc. - seen as a partial solution or a tentative to fight high levels of this effluent - are constantly increasing. Until present, the process costs for covering any chemical degradation or for definitive stocking $\mathrm{CO}_{2}$ appear prohibitory for stopping, even partially, the growing excesses of this disturbing greenhouse effluent.

To come back to electrochemistry, any elementary process that could bind the oneelectron cathodic reduction to the reversible sequestration of $\mathrm{CO}_{2}$ both at carbonaceous materials (essentially graphite, graphene) or at transition metals for creating thick carboxylated layers at different solid conductors (simplicity for functionalization, anticorrosion gain) could be considered. This mode of sequestration certainly deserves to be generalized and applied to a wide variety of materials.

Until now, a few reports concerning gold, silver, and copper underline the interest to create thick solid carboxylated interfaces for further applications [15-17], particularly the developments of unexpected reversible $\mathrm{CO}_{2}$ stocking-immobilization processes. Besides the interest of carboxylating a wide variety of materials, the aim of the present contribution is to focus on the very peculiar feature of precious metals like platinum and palladium to concomitantly stock different electrolytes thus allowing one to cathodically generate, under superdry conditions, the iono-metallic forms comparable in a certain way to well-known phases of Zintl and Corbett [18]. Rhodium, considered as a precious metal, and apparently 
showing a cathodic behaviour analogous to that of $\mathrm{Pt}$ and $\mathrm{Pd}$ is included in the present report. The basic question therefore arises: is the concomitant insertion of electron(s), salt(s), and $\mathrm{CO}_{2}$ conceivable and if yes, in which order. Such a concept could be the basis of the building of new sort(s) of multi-purpose reducing materials reversibly generated within a quite negative range of potentials. Additionally, as already stressed with gold [16], the cathodic insertion of a gas would be equivalent to a chemically reversible process.

\section{Concerning experimental conditions}

As mentioned above, the conversion and/or the elimination of $\mathrm{CO}_{2}$ under catalytic conditions at room temperature in aqueous solutions or in organic polar solvents mixed with proton donors were achieved generally at smooth transition metal electrodes and a large choice of catalysts, albeit unfortunately without any remarkable selectivity [4]. On the contrary, totally different results are achieved in dry polar aprotic solvents containing exclusively tetramethylammonium $\mathrm{TMA}^{+}$salts (essentially associated with tetrafluoroborate and perchlorate). Other commercially available $\mathrm{TMA}^{+}$salts can be used as well, but since a part of the present study concerns the experiments within the anodic range, it appears judicious for the moment to leave aside the tetramethylammonium halides. Importantly, it is essential to focus our interest on the high specificity of $\mathrm{TMA}^{+}$salts for the present study, because these electrolytes are the only tetraalkylammonium salts not subject to Hofmann degradation (serving as an efficient source of proton, particularly in aprotic polar solvents generally employed as un-buffered). They consequently prevent, in the course of the charge process, the protonation of the $\mathrm{CO}_{2}$ anion radical regarded in the present approach as the key intermediate of the electrochemical process. This hypothesis was previously checked at gold or silver cathodic surfaces with a large panel of tetra-alkylammonium $\left(\mathrm{TAA}^{+}\right)$electrolytes.

Practically, making Pd, Pt, and $\mathrm{Rh}$ electrodes is quite simple (sealing a metal wire in an appropriate glass tube). Their size was $1 \mathrm{~mm}$ diameter with $\mathrm{Pt}$ and $\mathrm{Pd}$, and only $0.5 \mathrm{~mm}$ with Rh. Electrodes were polished before use onto silicon carbide paper (Struers 500 and 1200) and rinsed with water, then alcohol and lastly with acetone. Dimethylformamide (DMF) and acetonitrile (ACN) of high purity were used after addition of neutral alumina activated under vacuum at $320{ }^{\circ} \mathrm{C}$ during four hours. Only moisture level of the electrolyte below $100 \mathrm{ppm}$ permits the electrolyte insertion into the concerned metals [19-21]. After potentiostatic electrolyses at the cathodic step that should correspond - see below - to the cathodic charge of the metal, as specifically described with $\mathrm{Pt}$ and $\mathrm{Pd}$ under superdry 
conditions [19] but also upon saturation of the solvent with carbon dioxide, the carboxylated plates or the disk electrodes are rinsed with water and acetone and then dried. These materials show a good stability to the atmosphere and moisture.

Layer FTIR analyses $\left\{v_{\mathrm{C}=\mathrm{O}} 700-1600 \mathrm{~cm}^{-1} 1, \delta_{\mathrm{CH}} 1440-1230 \mathrm{~cm}^{-1}, \delta_{\mathrm{OH}} 930 \mathrm{~cm}^{-1}\right\}$ support the evidence for a large and stable modification of the concerned surfaces. Moreover, EDS spectra confirm the presence of a carbon signal.

\section{Results. Cathodic carboxylation of precious metals}

Quite certainly, the cathodic reactivity of Pd and Pt toward carbon dioxide appears very different from the results previously reported with gold [18]. A fundamental discrepancy would lie in the fact that the reduction step assigned to the sequestration of $\mathrm{CO}_{2}$ (steps $\mathbf{C 1}$, Figure 1) that is totally separated from that of the metal charge process (occurring in $\mathbf{C 2}$, as fully established with Pt and Pd previously under comparable experimental conditions, but in the absence of carbon dioxide [20]). Therefore, the present process points out the concomitance of two insertion phenomena mixing, at potentials $<-1.8 \mathrm{~V}$, the insertion of $\mathrm{CO}_{2}$ and that of the electrolytic inclusion of the salt.

\section{Figure 1}

It is established with both metals that the first cathodic step C1 does not correspond to a strict charge process of the metal, but is assigned to the catalytic reduction of $\mathrm{CO}_{2}$ at these metals generating the anion radical which is capable, under the given experimental conditions, to lead to the insertion that implies only carbon dioxide. Note that step $\mathbf{C 1}$ generally vanishes after one scan: such a disappearance is assigned to a dense interfacial deposition of $\mathrm{CO}_{2}$ via its reduced form provoking a profound loss of the catalytic process. One may expect that it is connected to the step A1 (anodic oxidation of metal- $\mathrm{CO}_{2}$ bonds present at the metal interface giving an efficient coverage of the surface and found out with tested precious metals). Still within the negative potential range, step $\mathbf{C 2}$ accounts for the specific cathodic charge already described with $\mathrm{Pt}$ and $\mathrm{Pd}[21]$ in the presence of $\mathrm{TAABF}_{4}$ under similar conditions that imply superdry media. This step also totally vanishes upon several successive scans (insertion of the electrolyte until the formation of a poorly conducting layer) [20-21]. Anodic oxidation of the modified surfaces allows recovering a virgin metal surface and therefore permits to assign this step to the anodic evolution of $\mathrm{CO}_{2}$. Under the given conditions $\left(\mathrm{TMABF}_{4}\right.$, saturated solution 
of $\mathrm{CO}_{2}$ at room temperature), the insertion degree was estimated (assuming a thick carboxylated metal layer) as $\Gamma_{\mathrm{MCO} 2} \approx 10^{-7} \mathrm{~mol} \mathrm{~cm}^{-2}$ ). It raises a fundamental question on the mechanism of insertion occurring at $\mathrm{E}<-2.2 \mathrm{~V}$ that could mix electrolyte and carbon dioxide in a complex modification of the external layer of the metal, possibly implying $\mathrm{CO}_{2}$ anion radical.

Carboxylation of smooth platinum may lead to a large change in the structure of the surface. EDS spectra confirm the presence of a carbon signal. Layer FTIR analyses $\left\{v_{\mathrm{C}=\mathrm{O}}\right.$ $\left.700-1600 \mathrm{~cm}^{-1}, \delta_{\mathrm{CH}} 1440-1230 \mathrm{~cm}^{-1}, \delta_{\mathrm{OH}} 930 \mathrm{~cm}^{-1}\right\}$ support the evidence of a large and stable modification of the concerned surfaces. The lack of the catalytic ability of carboxylated $\mathrm{Pt}$ electrodes is illustrated in Figure 2 for allowing significantly cathodic scans until more negative potentials.

Figure 2

Similarly, the charge-discharge process of a smooth surface of rhodium in the presence of $\mathrm{CO}_{2}$ is displayed in Figure 3. Step $\mathbf{C 1}$ is still assigned to the catalytic reduction of $\mathrm{CO}_{2}$ at the electrode surface. The charge of the metal starts at potentials $<-2 \mathrm{~V}$ vs. $\mathrm{Ag} / \mathrm{AgCl}$. Similarly to palladium, the discharge is obtained at a potential of $1.5 \mathrm{~V}$. A single anodic scan allows recovering incorporated $\mathrm{CO}_{2}$ (peak A1).

\section{Figure 3}

Specifically, step A1 could stand for the specific oxidation of $\mathrm{Rh}-\mathrm{CO}_{2}^{-}$bond. Additionally, it was checked that the surface carboxylation of rhodium also occurs: this is supported in particular by a simple marking of carboxylic groups with substituted primary aromatic amines (e.g. 1-aminoanthraquinone that shows a reversible cathodic step at $-0.84 \mathrm{~V}$ assigned to the reduction of amido-anthraquinone (Figure 3, B). The amount of anthraquinone moieties immobilized at the surface has then been estimated to be $3.1 \times 10^{-9} \mathrm{~mol} \mathrm{~cm}^{-2}$ (caption of Figure 3). This coverage value sounds fundamentally different of those disclosed by means of the integration of step A1 that leads to much higher values (around $10^{-7} \mathrm{~mol} \mathrm{~cm}^{-2}$ ) that are quite close to those obtained with $\mathrm{Pt}$ and $\mathrm{Pd}$. They are possibly due to the formation of a highly porous interface made of micro spheres typical for the cathodic charge of $\mathrm{Pd}$ and $\mathrm{Pt}$ [21]. 


\section{Conclusive remarks.}

It is clear that the behavior of platinum towards $\mathrm{CO}_{2}$ under cathodic polarization is very close to that of palladium. The data presented with $\mathrm{Rh}$ conform with the occurrence of a charge of the metal, but no precise evidences in that sense were given so far. Recall that $\mathrm{Pt}$ and $\mathrm{Pd}($ denoted $\mathrm{M})$ may be charged in the presence of salts $\mathrm{C}^{+}, \mathrm{A}^{-}$leading to the iono-metallic structures of general stoichiometry $\left[\mathrm{Mn}^{-} \mathrm{C}^{+},\left\{\mathrm{C}^{+} \mathrm{A}^{-}\right\}\right]$with $\mathrm{n}=2$ or 4 in the case of $\mathrm{Pt}$ and $\mathrm{Pd}$, respectively.

The reduction of $\mathrm{CO}_{2}$ strongly depends on the nature of the metals used as cathode material. Thus, the reduction-insertion process observed with carbon dioxide should obey a form of exchange between the iono-metallic form shown above and their reducing power was already established [19] in the presence of $\pi$-acceptors used as markers. A surface process based on the exchange between the inorganic anion $\mathrm{A}^{-}$according to the process displayed below could be proposed. Additionally, iono-metallic complex is certainly candidate to act partly as reducing species towards carbon dioxide (reaction (2)). Moreover, metallic complexes implying either electrolyte or carbon dioxide anion are unstable toward the atmosphere (reaction (3).

$$
\begin{aligned}
& {\left[\mathrm{M}^{-} \mathrm{C}^{+},\left\{\mathrm{C}^{+} \mathrm{A}^{-}\right\}\right]+\mathrm{CO}_{2}^{--} \longrightarrow\left[\mathrm{M}^{-} \mathrm{C}^{+},\left\{\mathrm{C}^{+} \mathrm{CO}_{2}^{-}\right\}\right]+\mathrm{A}^{-}} \\
& {\left[\mathrm{M}^{-} \mathrm{C}^{+},\left\{\mathrm{C}^{+} \mathrm{A}^{-}\right\}\right]+\mathrm{CO}_{2} \longrightarrow \mathrm{CO}_{2}^{--}+\mathrm{nM}+\left\{\mathrm{C}^{+} \mathrm{A}^{-}\right\}+\mathrm{C}^{+}} \\
& {\left[\mathrm{M}^{-} \mathrm{C}^{+},\left\{\mathrm{C}^{+} \mathrm{A}^{-}\right\}\right]+\mathrm{O}_{2} \longrightarrow \mathrm{O}^{--}+\mathrm{n} \mathrm{M}+\left\{\mathrm{C}^{+} \mathrm{A}^{-}\right\}+\mathrm{C}^{+}}
\end{aligned}
$$

Alternatively, the carboxylated metallic complexes may exchange $\mathrm{CO}_{2}$ with organic $\pi$-acceptors leading, under de-aerated conditions (argon atmosphere), to the $\pi$-acceptor anionradical (especially with $\mathrm{C}^{+}=\mathrm{TMA}^{+}$). Such $\mathrm{Pd}$ and $\mathrm{Pt}$ complexes, and possibly stabilized $\mathrm{Pt} / \mathrm{Pd}$ colloids under very different experimental conditions [22], could be applied to incorporate both $\pi$-acceptor anion-radicals as nucleophiles and reduced forms of carbon dioxide.

Acknowledgments: Professor V. Jouikov (University of Rennes 1) is warmly thanked for his efficient and kind remarks about the manuscript. 


\section{References}

[1] P. Barnier, S. Lefrant, Le carbone dans tous ses états (The carbon in all its states), Gordon and Breach Science Publishers, (1997) and references cited.

[2] C. Dano, J. Simonet, Cathodic reactivity of graphite with carbon dioxide: an efficient formation of carboxylated carbon materials, J. Electroanal. Chem. 564 (2004) 115-121.

[3] V. Jouikov, J. Simonet, Efficient cathodic carboxylation of graphene: Building a new versatile material, Electrochem. Commun. 43 (2014) 67-70.

[4] D. Pletcher, The cathodic reduction of carbon dioxide-What can it realistically achieve? A mini review, Electrochem. Commun. 61 (2015) 97-101.

[5] I. Ganesh, Electrochemical conversion of carbon dioxide into renewable fuel chemicals The role of nanomaterials and the commercialization, Renewable and Sustainable Energy Reviews, 59 (2016) 1269-1297.

[6] J. H. Q. Lee, S. J. L. Lauw, R. D. Webster, The electrochemical reduction of carbon dioxide $\left(\mathrm{CO}_{2}\right)$ to methanol in the presence of pyridoxine (vitamin $\mathrm{B}_{6}$ ), Electrochem. Commun. 64 (2016) 69-73.

[7] W. Lv, R. Zhang, P. Gao, L. Lei, Studies on the faradaic efficiency for electrochemical reduction of carbon dioxide to formate on tin electrodes, J. Pow. Sources, 253 (2014) 276281.

[8] Z-L. Wang, C. Li, Y. Yamauchi, Nanostructured nonprecious metal catalysts for electrochemical reduction of carbon dioxide, Nano Today, 11 (2016) 373-391.

[9] S. Bashir, Sk.S. Hossain, S. ur Rahman, S. Ahmed, A-A. Amir, M. M. Hossain, Electrocatalytic reduction of carbon dioxide on $\mathrm{SnO}_{2} / \mathrm{MWCNT}$ in aqueous electrolyte solution, J. $\mathrm{CO}_{2}$ Utilization 16 (2016) 346-353.

[10] A. Q. Fenwick, J. M. Gregoire, O. R. Luca, Electrocatalytic reduction of nitrogen and carbon dioxide to chemical fuels: challenges and opportunities for a solar fuel device, Special issue on Artificial Photosynthesis, Journal of Photochemistry \& Photobiology, B: Biology 152 (2015) A 47-57.

[11] A. Grace, S. Y. Choi, M. Vinoba, M. Bhagiyalakshmi, D. H. Chu, Y. Y. Yoon, S. C. Nam, S. K. Jeong, Electrochemical reduction of carbon dioxide at low overpotential on a polyaniline $/ \mathrm{Cu}_{2} \mathrm{O}$ nanocomposite based electrode, Appl. Energy, 120 (2014) 85-94. 
[12] M. García, M. J. Aguirre, G. Canzi, Kubiak, P. Clifford, M. Ohlbaum, M. Isaacs, Electro and photoelectrochemical reduction of carbon dioxide on multimetallic

porphyrins/polyoxotungstate modified electrodes, Electrochim. Acta 115 (2014) 146-154.

[13] J. Qiao, M. Fan, Y. Fu, Z. Bai, C. Ma, Y. Liu, X. Zhou, Highly-active copper oxide/copper electrocatalysts induced from hierarchical copper oxide nanospheres for carbon dioxide reduction reaction, Electrochim. Acta. 153 (2015) 559-565.

[14] Y. Zhao, Z. Zhang, X. Zhao, R. Hao, Catalytic reduction of carbon dioxide by nickelbased catalyst under atmospheric pressure, Chem. Eng. J. 297 (2016) 11-18.

[15] J. Simonet, Insertion of $\mathrm{CO}_{2}$ into silver in a large extent, Electrochem. Commun. 58 (2015) 11-14.

[16] V. Jouikov, J. Simonet, Cathodic carboxylation of gold in thick $\left\{\mathrm{Au}-\mathrm{CO}_{2}\right\}_{\mathrm{n}}$ layers. A model for a reversible electrochemical sequestration of $\mathrm{CO}_{2}$, Electrochem. Commun, 59

(2015) 40-42.

[17] J. Simonet, Large-scale cathodic carboxylation of copper surfaces, Electrochem. Commun. 76 (2017) 67-70.

[18] P. Hapiot, J. Simonet, Reduction of platinum under superdry conditions. An electrochemical approach, Electroanal. Chem. 23 (2010) 105-169.

[19] J. Simonet, Electron transfer at platinum and palladium interfaces in super-dry electrolytes. Generation of iono-metallic layers. A mini-review, Electrochem. Commun. 53 (2015), 15-19.

[20] C. Cougnon, J. Simonet, Cathodic reactivity of platinum and palladium in electrolytes under superdry conditions, Platinum Metals Rev., 46 (3) (2002) 94-105.

[21] J. Simonet, The platinized platinum interface under cathodic polarisation, Platinum Metals Rev. 50 (4) (2006) 180-193.

[22] M.T. Reetz, M. Winter, R. Breinbauer, T. Thurn-Albrecht, W. Vogel, Sizeselective electrochemical preparation of surfactant-stabilized Pd-, Ni- and $\mathrm{Pt} / \mathrm{Pd}$ colloids, Chemistry, A European Journal, 7 (5) (2001) 1084-1094. 


\section{Figure captions}

\section{Figure 1}

Carboxylation of smooth platinum (left, two cathodic scans) followed by two anodic responses and (right) that of palladium deposited in a very thin layer obtained by electrolysis onto a glassy carbon electrode $\left(\right.$ area $\left.=0.8 \mathrm{~mm}^{2}\right)$ in a super-dry DMF saturated with $\mathrm{CO}_{2}(\approx 0.2$ mol L $\left.{ }^{-1}\right)$. Scan rate: $50 \mathrm{mV} \mathrm{s}^{-1}$. Electrolyte: $0.1 \mathrm{M} \mathrm{TMABF}_{4}$. For comparison, the reduction of $\mathrm{CO}_{2}$ at glassy carbon ( $\mathrm{GC}$, absence of catalysis) is displayed under comparable conditions.

\section{Figure 2}

Carboxylation of platinum for yielding tailored surfaces. (A) SEM image of a smooth platinum surface modified after a single scan until $-1.4 \mathrm{~V}$ (scan rate: $50 \mathrm{mV} \mathrm{s}^{-1}$ ) in the presence of carbon dioxide in DMF and then sonicated. (B) Then, the produced surface (in the course of one scan) is used as a modified cathode material in a solution of DMF containing only $\mathrm{TBABF}_{4}$ allowing potential limit of -2.4 Volt (shown in (a) in red). The voltammetry of anthracene $\left(4.2 \times 10^{-3} \mathrm{M} \mathrm{L}^{-1}\right)$ is displayed in (b) at smooth platinum electrode and compared in (c) at the same electrode modified by carboxylation.

\section{Figure 3}

A: Reduction $(\mathbf{C 1})$ followed by oxidation (A1) of a Rh micro-electrode (surface area: 0.2 $\mathrm{mm}^{2}$ ) in the presence of $\mathrm{CO}_{2}$ at saturation. Electrolyte: $\mathrm{DMF}+0.1 \mathrm{M} \mathrm{TMeABF} 4$. Scan rate: $50 \mathrm{mV} \mathrm{s}^{-1}$. Cathodic scans $\mathbf{1}$ and $\mathbf{2}$ are swept first and the produced surface is immediately submitted to an anodic exploration.

B: Modification of a rhodium cathodically modified surface by dipping the carboxylated layer (obtained by a scan up to $-2.0 \mathrm{~V}$ ) in a solution of a $0.1 \mathrm{M}$ 1-aminoanthraquinone $\left(\mathrm{H}_{2} \mathrm{NAQ}\right.$ ) in $\mathrm{DMF}$ during $5 \mathrm{~min}$. Sonication and rinsing in acetone. Cycling achieved in $\mathrm{DMF}+\mathrm{TBuABF}_{4}$. Scan rate: $50 \mathrm{mV} \mathrm{s}^{-1}$. The integration at the first scan (step at $-0.8 \mathrm{~V}$ ) attests a coverage level of $\Gamma_{\mathrm{AQ}}=3.1 \times 10^{-9} \mathrm{~mol} \mathrm{~cm}^{-2}$. 


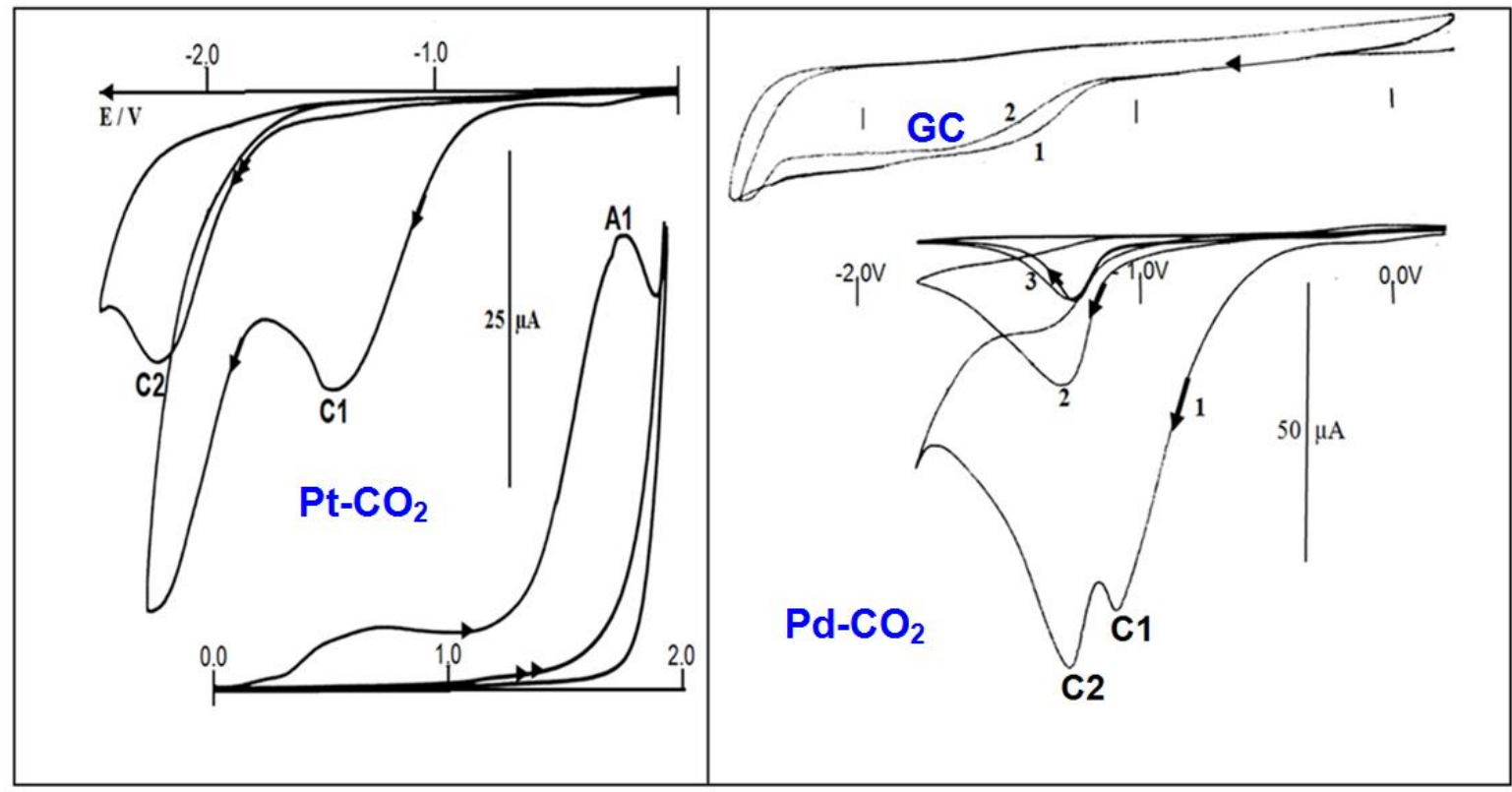

Figure 1

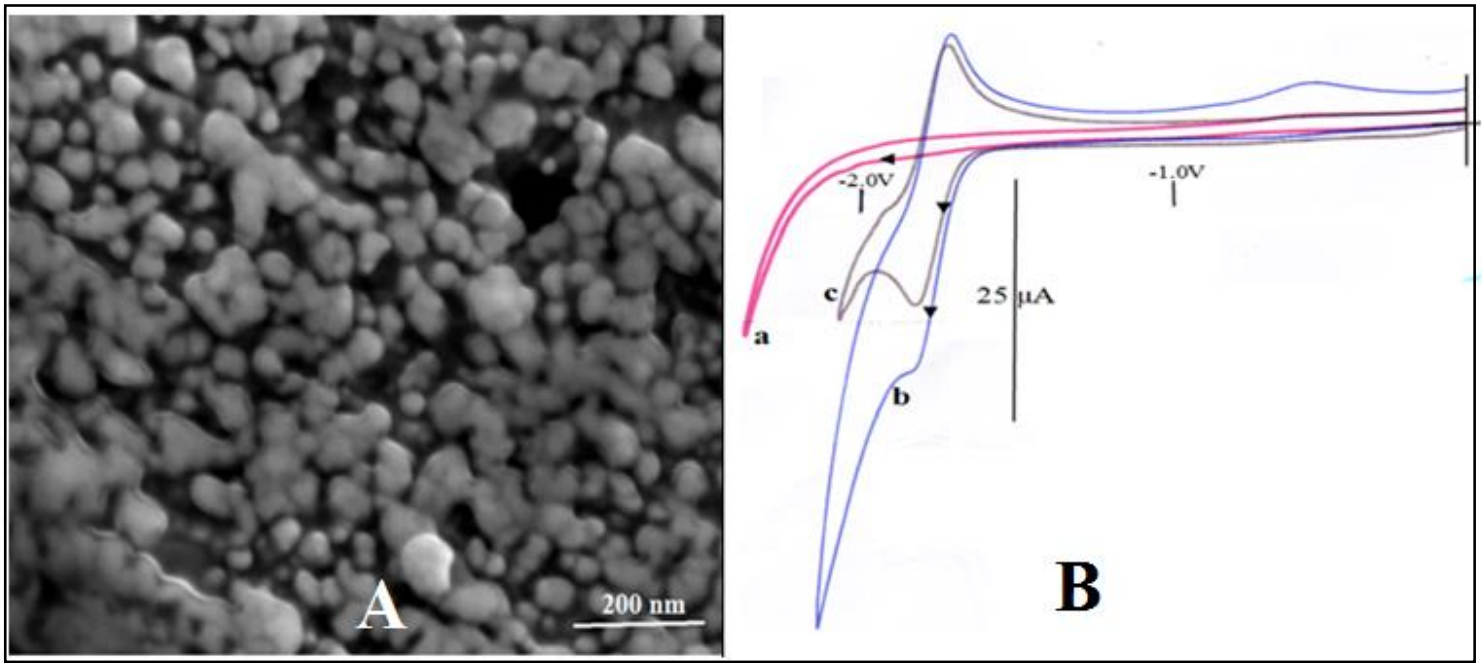

Figure 2 


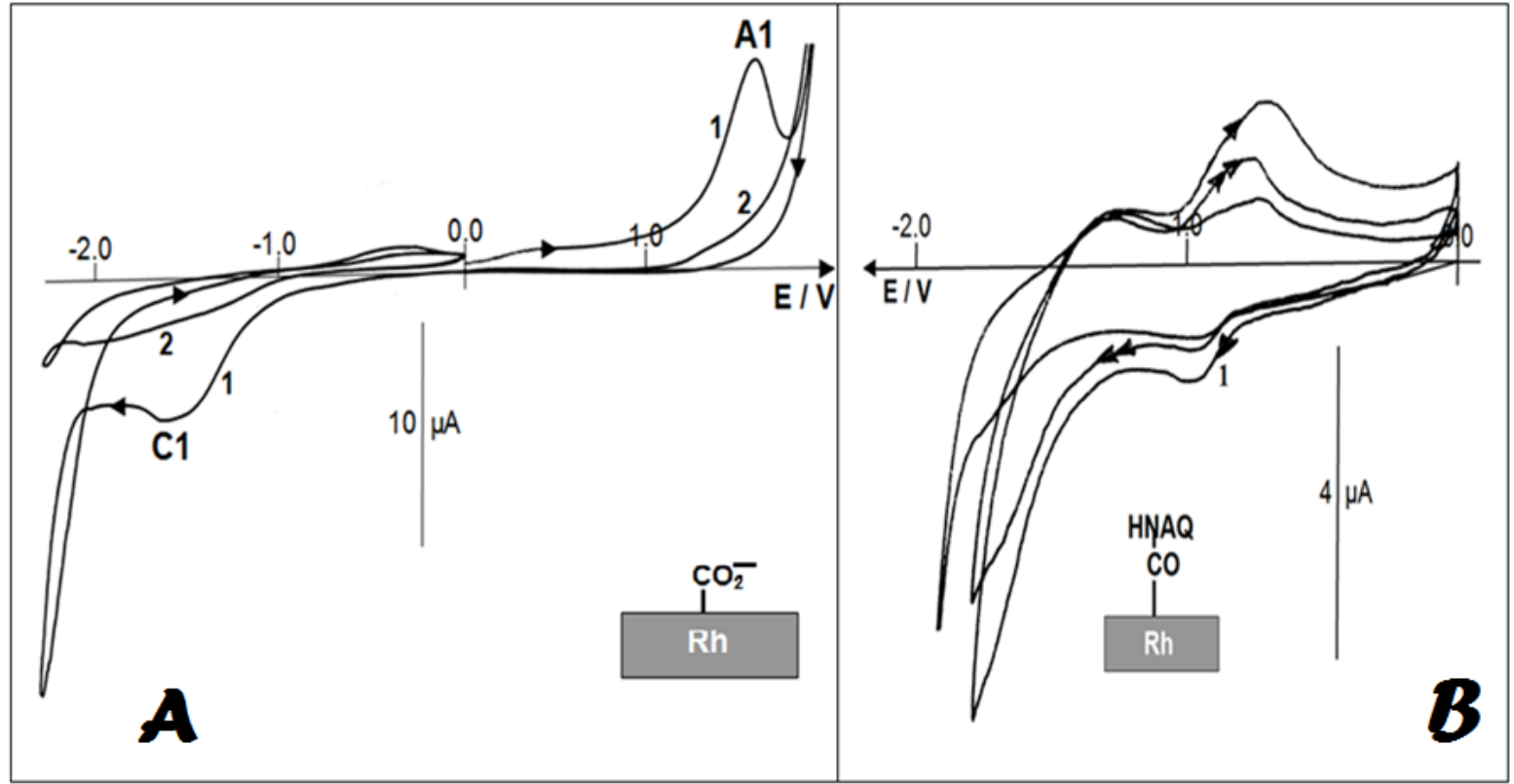

Figure 3 


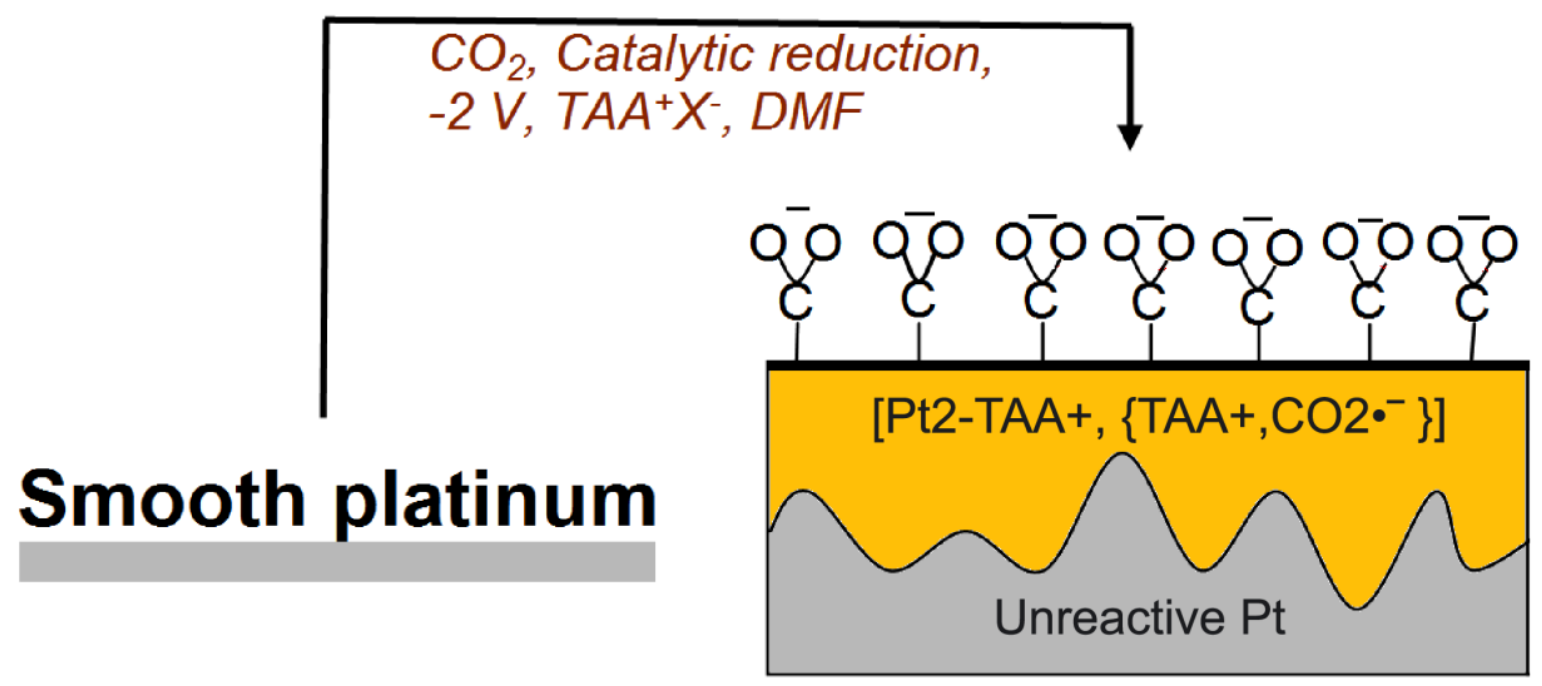

Graphical abstract 
Highlights

- The reduction of $\mathrm{CO}_{2}$ at $\mathrm{Pt}, \mathrm{Pd}$, and $\mathrm{Rh}$ surfaces leads to efficient carboxylation of these metals.

- Insertion of $\mathrm{CO}_{2}$ into these metals occurs in a polar aprotic medium containing tetramethylammonium salts.

- Carboxylation definitively suppresses the catalytic activity of the metal.

- Functionalization of the carboxylate groups permits easy surface modification. 